\title{
Evaluation of Prescribing Pattern of the Referring Cases at Sudan National Health Insurance Fund
}

\author{
Shagali Hana $\mathrm{EH}^{1 *}$, Sahal Elmardi $\mathrm{A}^{2}$ and Mousnad $\mathrm{MA}^{3}$ \\ ${ }^{1}$ Department of Pharmacy Practice, Faculty of Pharmacy International University of \\ Africa (IUA), Sudan \\ ${ }^{2}$ Saudi Commission for Health Specialties, Saudi Arabia \\ ${ }^{3}$ Faculty of Pharmacy, International University of Africa (IUA), Sudan
}

\section{Research Article}

Volume 2 Issue 4

Received Date: July 09, 2019

Published Date: July 19, 2019

DOI: $10.23880 /$ jqhe- 16000131

*Corresponding author: Hana Elsheikh Hassan Shagali, Head of the Pharmacy Practice Department, Faculty of Pharmacy, International University of Africa (IUA), Khartoum, Sudan, Tel: +249115986685; Email: Hana_elsheikh@yahoo.com

\section{Abstract}

Background: Irrational drug use is a worldwide health problem. A high rate of medical utilization, especially in antibiotics prescribing were observed in the National Health Insurance Fund in Sudan. The aim of this study was to evaluate prescribing pattern.

Methods: A retrospective cross-sectional descriptive study was conducted using World Health Organization (WHO) core drug use indicators for three months January, February and March 2011 in the Referring case office in the NHIF.

Results: A total of 396 prescriptions were collected, 99 prescriptions from each of the selected four states in Sudan (North, Gazirea, North Kordoufan, and Kassala) for three months January, February and March. The overall results for the four states verify that the average number of drug per prescription was $2.87 \pm 1.72$. 38.32\% of drugs were prescribed by generic name. Percentage of drug prescribed from Essential drug list of Sudan was $91.52 \%$. Antibiotics and injections encountered were $47.73 \%$, and $29.79 \%$ respectively.

Conclusion: The finding of this study shows a trend towards irrational prescribing. So, there is great need for effective intervention strategies to encourage the physicians and pharmacists in promoting more rational drug use.

Keywords: Irrational Prescribing; Sudan; National Health Insurance Fund; Referring Cases

\section{Introduction}

The irrational use of drugs is a worldwide problem which affects the health care system as well as society. More than $50 \%$ of all medicines are prescribed, dispensed or sold inappropriately while $50 \%$ of patients fail to take them correctly. Moreover, about one-third of the world population lacks access to essential medicines [1].

The rational use of drugs is an important element of the health care system and plays an important role in the quality of drug therapy improvement and the cost- health. 


\section{Journal of Quality in Health Care \& Economics}

The rational use of medicine as defined by WHO postulates that "patients receive medications appropriate to their clinical needs, in doses that meet their own individual requirements, over an adequate period of time and at the lowest cost to them and their community" [2].

Different impacts had been noticed of the irrational use of drugs, this include; increase risk of adverse effects, reduce efficacy of drugs, emergence of antimicrobial resistance, and the over use of injections might lead to serious infections [3].

One of the important concepts that ensure the rational drug use is the essential drug concept. In Sudan, the Ministry of Health formulated a national drug policy in 1981, through which a national list of essential drugs is selected. This list was revised and updated frequently and for latest version in 2014 [4]. Studies confirmed that these lists a satisfactory level of nearly $80 \%$ availability of the surveyed medicines in the county $[5,6]$.

Sudan is an African country that had been divided into 18 states. The political system is presidential republic and a federal system, with clearly demarcated levels of governments; federal, state and local governments.

According to Regional health systems observatory, WHO 2006,Sudan health system profile states that in 2000 infant mortality rate was 68 per 1000 live birth, maternal mortality rate was 509 per100000 live births, and the total fertility rate was 5.9 (7). In Sudan, health services are provided by different ways including Federal and State ministries of health, Armed forces, Police, universities, private sector and civil society [7].

National Health Insurance Fund (NHIF) is an organization aimed to provide medical services to the insured people, through the National Insurance Card, with sustainability at an affordable cost. It is a cost sharing system financed by $10 \%$ of employee's salary $6 \%$ by the employers and $4 \%$ by workers [8]. Consultation, laboratory investigations, surgical procedures are free but $25 \%$ of the medicine cost is paid by the patient. Referring cases office is one of the sectors in NHIF that deal with the cases need further treatment or to solve any defect in health services in the other states.

The current study provides comprehensive descriptive analysis of the prescribing pattern of drugs and focus on the consumption oral antibiotics. The study might help researchers for further studies and policy makers will take it as base information for design planning and priority setting.

\section{Methods}

This study is a basic cross sectional study design. It involves comparison of patients' records in order to measure drug use and to compare prescribing practices. The study was designed using the methods described in the WHO manual, "How to investigate drug use in health facilities" [9]. The data is recorded in a designed form. The study was conducted at National Health Insurance Fundoffice of referring cases- Khartoum State. The period of the study was from the January Its 2011 till 31st March 2011.

Prescriptions of insured patients under NHIF referred from different states to referring cases office in Khartoum were the population of the study.

\section{The Sampling Method was a Multistage Sampling:}

- Simple random sampling from 4 regions in Sudan (15 states), that ended up with 4 sates; Middle (Gazera state), North (North state), West (North kurdofan state), East (Kassala state)

- Simple random sampling from each of the 4 states, i.e. 33 prescriptions from each state.

The sampling frame was 3 months prescriptions from each of the 4 states, that giving rise to 99 prescriptions from each state, ended up by the total number of prescriptions equal to 396 prescriptions (sample size).

The study was designed using the methods described in the WHO manual [9]. Selected drug use indicators as suggested by WHO/INRUD (International Network for Rational Use of Drugs) were used in this study. These indicators include:

\section{Prescribing Indicators}

$>$ Average number of medicines per prescription.

$>$ Percentage of medicines prescribed by generic name.

$>$ Percentage of prescriptions with an antibiotic prescribed.

$>$ Percentage of prescriptions with an injection prescribed.

$>$ Percentage of medicines prescribed from an essential drug list (EDL).

Retrospective data was collected from the records in the referring cases office, Khartoum state. A total of 396 prescriptions were collected, 99 prescriptions from each of the four states for January, February and March. The data was collected in a standard WHO form. 


\section{Journal of Quality in Health Care \& Economics}

During the analysis of data, all variables were calculated descriptively by using the Excel program (Microsoft ${ }^{\circledR}$ Excel, 2000). Averages and percentages were produced when appropriate.

The data analysed with the SPSS (Statistical Package for Social Sciences) software version 17. Descriptive analysis and frequency distribution was used to describe and compare the prescriptions' characteristics, prescription practices.

\section{Results}

\section{Prescribing Pattern-Selected WHO/INRUD Drug Use Indicators}

Average number of drugs per encounter: The average number of drugs per encounter was 3.71 in Gazira state, 2.51 in North state, while in North Kurdofan state 3.06, and 2.75 in Kassala state. The overall average number of drugs per prescription was $2.87 \pm 1.72$ drugs in all four states under study. The median was 3 drugs per prescription. The maximum number of drugs prescribed for a patient was 11 drugs found in Gazira state, 10 drugs in North state, 9 drugs in North kurdofan state, and 7 drugs in Kassala state. The results are demonstrated in figure 1 .

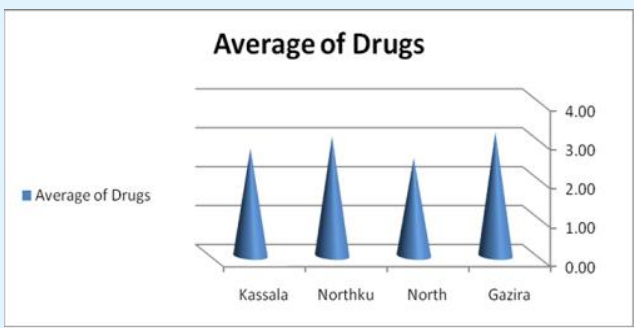

Figure 1: Average number of drugs per encounter.

Percentage of drugs prescribed by generic name: $\mathrm{A}$ percentage of $43.95 \%, 37.90 \%, 37.95 \%$, and $33.46 \%$ of drugs were prescribed by generic names in Gazira state, North state, North kurdofan state, and in Kassala state, respectively. The overall average was $38.32 \%$. The maximum number of drugs prescribed by generic name in one prescription was 8 drugs and this was found in Gazira state, while the maximum number of drugs prescribed by trade name in one prescription was drugs 6 and this was found in Kssala state. The detailed results are illustrated in figure 2 .

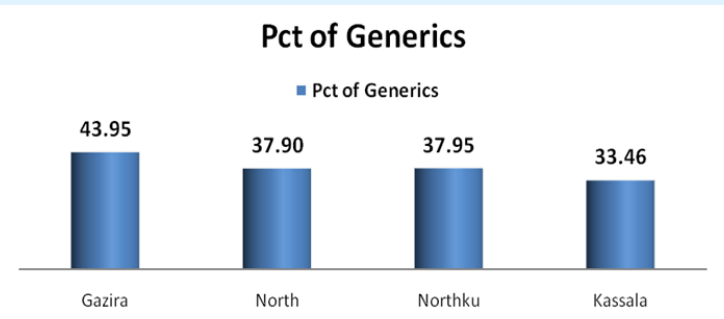

Figure 2: Percentage of drugs prescribed by generic name.

Percentage of encounters with an antibiotic prescribed: The percentage of prescriptions containing antibiotics was $53.54 \%, 48.48 \%, 48.48 \%$, and $40.40 \%$ in Gazira state, North state, North kurdofan state, and in Kassala state respectively. The overall average was $47.73 \%$. The results are shown in figure 3.

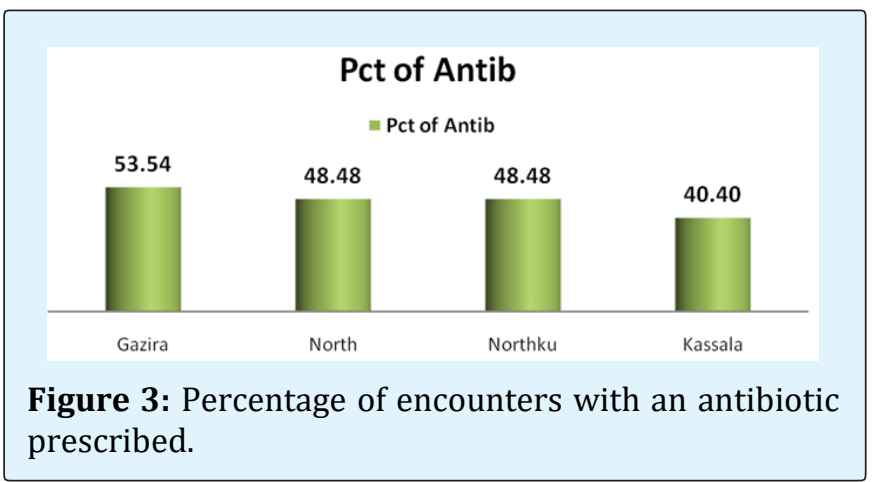

Percentage of encounters with an injection prescribed: The availability of prescriptions contained injectable drugs was $37.37 \%, 25.25 \%, 32.32 \%$ and 24.24 $\%$ in Gazira state, North state, North kurdofan state, and in Kassla state respectively. The overall average was $29.79 \%$ encounters with prescribed injection. The results are shown in figure 4.

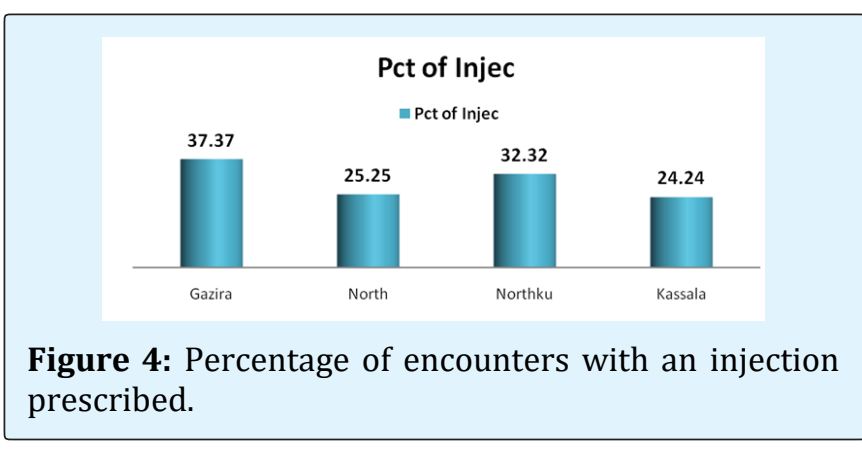




\section{Journal of Quality in Health Care \& Economics}

\section{Percentage of drugs prescribed from essential drug} list:

From all drugs prescribed in the prescriptions collected from all states studied, 92.68\%, $93.15 \%, 89.44$ and $89.71 \%$ of drugs were prescribed from the EDL in Gazira state, North state, North kurdokan state, and in Kassala state, respectively. The maximum number of drugs prescribed in one prescription from EDL was 9 drugs and it was found in Gazira state. The overall average was $91.52 \%$. The detailed results are illustrated in figure 4.5 .

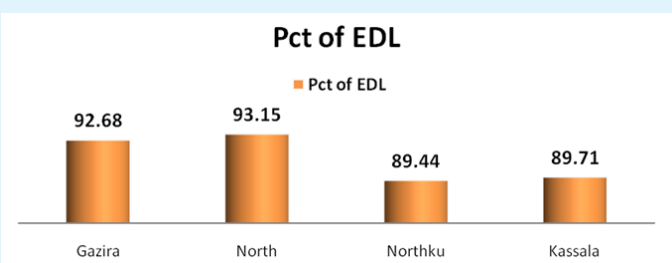

Figure 5: Percentage of drugs prescribed from essential drug list.

Summary of drug prescribing indicators: The below table $1 \&$ the figure 6 show the results of the five drug prescribing indicators for the four selected states.

\begin{tabular}{|c|c|c|c|c|}
\hline Prescribing indicators & Gazira & North & Northkurdofan & Kassala \\
\hline Average number of drugs & 2.75 & 3.06 & 2.51 & 3.17 \\
\hline Percentage of drugs by generics & 33.46 & 37.95 & 37.9 & 43.95 \\
\hline Percentage of encounter with an Antibiotics & 40.4 & 48.48 & 48.48 & 53.54 \\
\hline Percentage of encounter with an Injection & 24.24 & 32.32 & 25.25 & 37.37 \\
\hline Percentage of drugs by essential drug list (EDL) & 89.71 & 89.44 & 93.15 & 92.68 \\
\hline
\end{tabular}

Table 1: Summary of drug prescribing indicators.

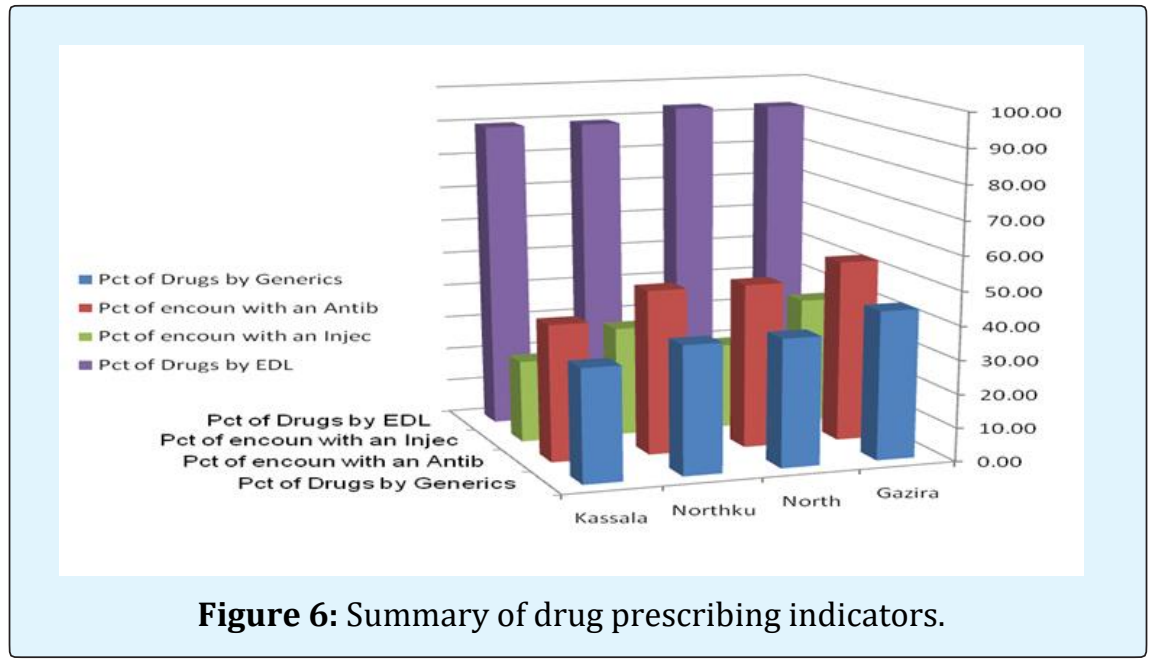

\section{Discussion}

This study aims to find out the current drug use practices, through prescribing pattern using WHO/INRUD prescribing indicators.

\section{Selected WHO/INRUD Prescribing Indicators}

These standard indicators provide general picture of the current prescribing habits and allow comparison with local and international results and help identify problematic areas, so policy makers could set intervention strategies. Such studies had been conducted in Malawi, Nigeria, Tanzania, and Uganda [10].

\section{Average Number of Drugs Per Encounter}

The average number of drugs per prescription is an important element in drug utilization studies [11]. It is used to assess poly pharmacy. No great variation in the value between the four states, but it noticeably high in Gazira state, where more interventions needed. The overall average was 2.87.The recommended WHO value for this indicator is to be less than two so the value in this study shows existing of polypharmacy. In other developing countries higher results were found [12]. For example, in Indonesia and Bangladesh, 3.8 and 4.1 drugs were the average number of drugs prescribed per encounter, respectively [13]. Eastern Nepal, India and 


\section{Journal of Quality in Health Care \& Economics}

Nigeria were 5.3, 3.75 and 3.5, respectively [14]. Other studies reported better values such as Saudi Arabia which was 2.1 and 1.3 in Zimbabwe $[15,16]$. In Sudan, a study conducted in Khartoum teaching hospital showed an average of 1.9 this indicates an increase in the value, which lead to unfavourable outcomes, as, increase cost of the drug , drug interactions, and ,or non-compliance [17].

\section{Percentage of Drugs Prescribed by Generic Name}

According to the concept of essential drugs, health workers should refer to drugs by their generic names. This indicator helps to measure the tendency of prescribers to prescribe by generic names as listed in the WHO list of the International Non-proprietary Names (INN).There was no different in the results between the four states. The overall average of drugs prescribed by generic in this study was $38.32 \%$. This value is quite low than that reported in the study conducted in Khartoum teaching hospital, it was $43.6 \%$. This reflects the deterioration in the trend towards generic name. The value is remarkably low from that of Iran which is $97.2 \%$ and India where it is $96.5 \%[14,18]$. That low value may be due to the effect of the promotion of drug manufacturing companies, and/or the unawareness of the prescribers by the advantage of prescribing by generic name. These advantages include reducing drug cost and assuring less dispensing errors.

\section{Percentage of Encounters with an Antibiotic Prescribed}

The results of the four states showed no great difference between them in prescribing trend of antibiotics. The overall average of prescribed antibiotics was $47.73 \%$, and this is less than that suggested by the WHO that less than $30 \%$ of prescriptions should contain antibiotics (How to investigate drug use in health facilities, 1993). The founding was less than that reported in Bangladesh, Nigeria and Pakistan were it was $72.5 \%$, $54.8 \%$ and $51 \%$ respectively [19-21]. Thus, overuse of antibiotics lead to emergence or resistance, super infections and or unwanted side effects.

\section{Percentage of Encounters with an Injection Prescribed}

$29.79 \%$ was the overall average of encounters with prescribed injections. The WHO recommended value is less than $10 \%$ [12]. This value is remarkably high than that reported in, Saudi Arabia 2.1\% and Indonesia where it was as low as $0.2 \%[13,15]$. But it was much better than that of India 74\%, and in Ghana, a study showed that the percentage of injection prescribed was $80.0 \%$ [22]. This reassembly high value not only increases the cost of therapy, but also the risk of parental infection.

\section{Percentage of Drugs Prescribed from Essential Drug List}

The average percentage of drugs prescribed from the EDL in different studied sates was $91.52 \%$.It is a quite good value in comparison to that reported in Burkina Faso, where it showed $88.0 \%$ of the drugs prescribed were those listed in their EDL in Tanzania (88\%), and Nepal (86\%) [13,23]. In Ghana, a study showed that $97.0 \%$ of the drugs prescribed were on their EDL [22]. Prescribing from the essential list reserve safety and effectiveness of the drugs, since these drugs are selected according to local disease prevalence, efficacy and the cost.

\section{Limitations of the Study}

\section{In this Study, the Following Limitations were Encountered}

- It did not cover all WHO/INRUD core indicators, so as to give a good view for the prescribing pattern.

- It was conducted in a single season, not showing seasonal variation which might affect morbidity pattern, particularly for the antibiotics prescribing pattern.

- No asses to the prescription with regard to the diagnosis, or the compliance of the patient.

- A major limitation is the absence of WHO local reference values, and lack of local similar studies which would serve as a base to assess the prescribing practices, and the oral antibiotics consumption.

\section{Conclusion}

The findings of this study, with regard to WHO/INRUD five prescribing indicators, showed that there is no great different in results between the four states that represent our country. The overall average of the indicators reflects that, the average number of drugs per prescription was remarkably higher than recommended by WHO, ensuring the existence of the polypharmacy.

There is a high trend of the health workers to prescribe in brand name, giving rise to high cost of prescription, and increase the risk of prescribing error. The prescribed antibiotics were high, which lead to emerge resistance, toxicity, and unwanted side effects. Although injection prescribing is high, but there is a fairly good tendency to prescribe from the EDL. 


\section{Journal of Quality in Health Care \& Economics}

Regarding the finding of this study, there is great need for further studies, and developing interventions to improve the prescribing habits.

- More studies should be conducted, for further identifying of the prescribing pattern problem.

\section{Policy Implications}

Continuous education and in-service training programmers for the prescriber should be designed to change the behavior towards good prescribing.

A standard treatment guideline (STG) must be developed, including number and type of drugs, route of administration and duration of treatment of the common illness.

The selection, procurement and supply of the drugs, should be by generic names, and from the EDL.

The promotion of the drugs by the manufacturers should be supervised and monitored.

Development and improvement of a curriculum in the medical colleges and health institutes, which involve rational drug, and its importance.

\section{References}

1. WHO (2002) Promoting rational use of medicines: core components. Geneva pp: 1-6.

2. WHO (1987) The Rational use of drugs: Report of the conference of experts, Nairobi, 25-29 November 1985 Geneva pp: 388.

3. Le Grand A, Hogerzeil HV, Haaijer-Ruskamp FM (1999) Interventions research in rational use of druga review. Health Policy and Planning 14(2): 89-102.

4. Mahmoud RK, Kheder SI, Ali HM (2014) Prescribing rationality in Khartoum state, Sudan: An update. Sudan Medical Monitor 9(2): 61-66.

5. Bazargani YT, Ewen M, de Boer A, Leufkens HGM, Mantel Teeuwisse AK (2014) Essential Medicines Are More Available than Other Medicines around the Globe. PLOS ONE 9(2): e87576.

6. Cheraghali AM, Idries AM (2009) Availability, affordability, and prescribing pattern of medicines in Sudan. Pharm World Sci 31(2): 209-215.

7. WHO (2006) Health System Profile -Sudan. Regional Health System Observatory.
8. Alshareef SaS A, Aboud E, Mousnad MA, Mustafa IE (2010) National Health Insurance, the recent development in health care system in Sudan; a focus on financing and delivery of pharmaceutical services.

9. WHO (1993) How to investigate drug use in health facilities (selected drug use indicators). WHO/DAP/931 Geneva.

10. Quick JD (1998) Health MSf, Drugs APoE, Vaccines. Managing Drug Supply: The Selection, Procurement, Distribution, and Use of Pharmaceuticals: Kumarian Press.

11. El Mahalli A (2012) WHO/INRUD drug prescribing indicators at primary health care centres in Eastern province, Saudi Arabia. 18(11): 1091-1096.

12. WHO (2011) Teacher's guide to good prescribing. WHO/EDM/PAR.

13. (1991) Bimo Field Testing of drug use indicators of INRUD: Report of a field trip to Indonesia, Bangladesh and Nepal. INRUD, Boston.

14. Jeetendra Kumar MMS, Kaith MC, Deka A, Gambhir SS (2010) Prescribing indicators and pattern of use of antibiotics among medical outpatients in a teaching hospital of Central Nepal. Journal of college of Medical Science-Nepal 6(2): 7-13.

15. Emmanuel James KA, Annas H Zarie, Omer MIIA (2003) Factors influencing rational drug use in primary health care centers in Qassim region, Saudia Arabia. Saudia Pharmaceutical Journal 11(3).

16. Hogerzeil HV, Ross Degnan D, Laing R, Ofori-Adjei D, Santoso B, et al. (1993) Field tests for rational drug use in twelve developing countries. The Lancet 342(8884): 1408-1410.

17. Awad AL, ahmed HH (2006) Drug use practice in khartoum teaching hospital, Khartoum state ,Sudan. European Journal of Clinical pharmacology 62(12): 1087-1093.

18. Kanakanbal S MN, Shalhi M (2001) Drug prescribing pattern in a tertiary care teaching hospital in Madirai. India Journal of Clinical Pharmacology 33: 223.

19. Rahman ZNR, Begum M (2009) Evaluation of prescribing pattern of the private practitioners by the undergraduate medical students. Bangladesh Journal of Pharmacology 2009(4): 73-75. 


\section{Journal of Quality in Health Care \& Economics}

20. Odusanya 00 (2004) Drug use indicators at a secondary health care facility in Lagos, Nigeria. Journal of Community Medicine and Primary Health Care 16(1): 21-24.

21. Hafeez A, Kiani AG, ud Din S, Muhammad W, Butt K (2004) Prescription and dispensing practices in public sector health facilities in Pakistan survey report. J Pak Med Assoc 54(4): 187-191.
22. Bosu WK, Adjei OD (2000) An audit of antibiotics prescribing practices, Health care facilities of west district of Ghana. Journal of West African Medical 19(4): 228-303.

23. Krause G, Borchert M, Benzler J, Heinmüller R, Kaba I, et al. (1999) Rationality of drug prescriptions in rural health centers in Burkina Faso. Health policy and planning 14(3): 291-298. 